\title{
Clostridium difficile infection in hospitals: a brewing storm
}

$\mathrm{O}$ n June 4 CMA7 published a report about an outbreak of Clostridium difficile-associated diarrhea (CDAD) involving several hospitals in Montréal. ${ }^{1}$ The magnitude of this outbreak needs to be better delineated, but clearly something unusual is happening, and it is essential that we learn why. Is this an exceptional event in Montréal, or will it become the rule for Canadian hospitals?

Two studies estimated the incidence of CDAD in Canada in the mid 1990s: the mean incidence in large hospitals was 3.1 and 5.9 per 1000 admissions, ${ }^{2,3}$ a finding consistent with published reports in the United States and Europe. . $^{4-7}$ The case-fatality rate for CDAD was $1 \%-1.5 \% .^{8} \mathrm{Be}-$ cause Canada has no ongoing surveillance system for CDAD, data on incidence trends are not available. Reports from other countries, however, suggest that CDAD is becoming both more frequent and more severe (see Table 1). Two months ago, the IDSA Emerging Infections Network launched a survey entitled "Clostridium difficile: Changing Patterns of Disease?" to evaluate physician's perception of CDAD incidence. Of 481 respondents, 129 (29\%) thought that their caseload had increased in the past 6 months, and 128 (29\%) reported encountering more severe or fulminant CDAD. Surveillance identified a more than 7 -fold increase in positive laboratory test results for $C$. difficile throughout the 1990s in the $\mathrm{UK}$, where CDAD is now a notifiable disease. ${ }^{10}$

\section{What is going on in Canada?}

Even without formal surveillance data, it is clear that the number of cases and deaths in hospitals in Montréal represent a substantial increase. Although it is difficult to estimate the con- tribution of CDAD to the death of patients in hospital, the most conservative estimate of attributable deaths for only 2 hospitals in Montréal (24 patients) corresponds to a quarter of the annual number of deaths previously estimated for the entire country. The problem is not limited to Montréal: at the Centre hospitalier universitaire de Sherbrooke, since 2002, an important increase in the number of new cases diagnosed by the microbiology laboratory was noted (see Fig. 1). Consequently, rates of nosocomial
CDAD increased from 2.1 cases per 1000 admissions in 2002 to 10 per 1000 in 2003, and could reach 18 cases per 1000 admissions in 2004 (unpublished data). An email poll of infectious disease physicians across Canada conducted in early June in preparation for this article, with 58 responses from 8 provinces, identified that the increase in incidence and severity of CDAD is currently limited to parts of Quebec (Montréal and the region south of the St-Lawrence River), although it may also be emerging in Ottawa (see Fig. 2).

Table 1: Reports of increases in incidence and severity of Clostridium difficile-associated diarrhea (CDAD)

\begin{tabular}{|c|c|c|c|}
\hline Source & Period & Outcome measure & Results \\
\hline $\begin{array}{l}\text { US National Nosocomial } \\
\text { Infection Surveillance } \\
\text { System }\end{array}$ & 1987-2001 & $\begin{array}{l}\text { CDAD among patients } \\
\text { admitted to intensive care unit } \\
\text { in hospitals with }>500 \text { beds }\end{array}$ & Doubling of incidence \\
\hline $\begin{array}{l}\text { UK Health Protection Agency } \\
\text { Communicable Disease } \\
\text { Surveillance Centre }^{10}\end{array}$ & 1986-2001 & $\begin{array}{l}\text { Voluntary laboratory } \\
\text { reporting system of stools } \\
\text { positive for } C \text {. difficile toxin }\end{array}$ & $\begin{array}{l}\text { From }<2000 \text { positive test } \\
\text { results per year in 1986/87 to } \\
>12000 \text { per year in 2000/01 }\end{array}$ \\
\hline \multirow[t]{2}{*}{ Oregon $^{11}$} & 1994-2000 & $\begin{array}{l}\text { All-cause } 90 \text {-day mortality } \\
\text { among patients with CDAD }\end{array}$ & $\begin{array}{l}3.5 \% \text { in a previous } \\
10-\text {-year cohort v. } 15.3 \% \text { in } \\
1994-2000 \text { cohort }\end{array}$ \\
\hline & & Colectomy & $7.6 \%$ in $1994-2000$ cohort \\
\hline Pittsburgh $^{12}$ & 1989-2000 & Fulminant colitis & $\begin{array}{l}\text { From } 0 \% \text { to } 3.2 \% \text { (mean } \\
1.6 \% \text { over } 10 \text { years) }\end{array}$ \\
\hline
\end{tabular}

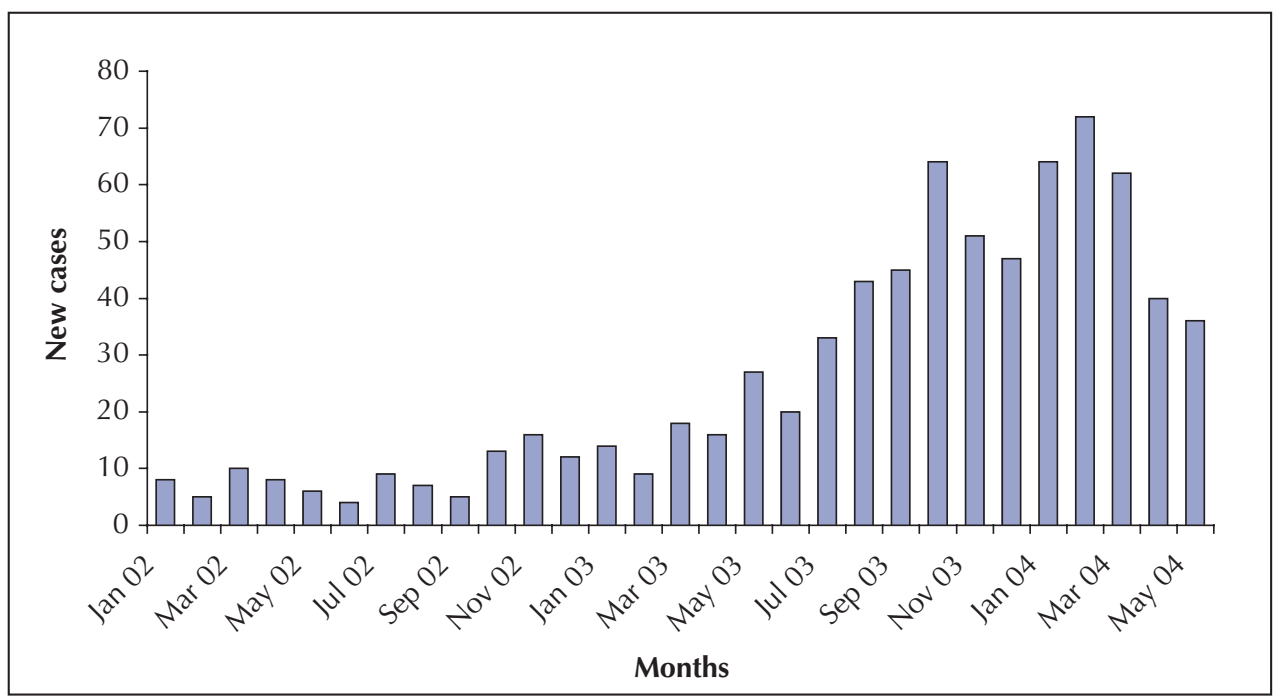

Fig. 1: New cases of nosocomial and community-acquired Clostridium difficile-associated diarrhea (CDAD; diagnosed by positive cytotoxin assay result) reported by the microbiology laboratory at the Centre hospitalier universitaire de Sherbrooke. 


\section{Why is it happening?}

Our aging population and changes in how we deliver health care mean that the average inpatient in Canadian hospitals is older and sicker than his or her counterpart of 10 years ago. Because age and comorbidity are risk factors for $\mathrm{CDAD}$, increasing rates of CDAD are, to some extent, expected and unavoidable. Changes in antibiotic therapy and the increasing use of proton pump inhibitors, interventions that may have other benefits, may also increase the risk of $\mathrm{CDAD}^{13}$ (see page 33 ). The aging infrastructure of hospitals and our willingness to tolerate hospital rooms with 4 patients and a single bathroom, less than 3 feet between beds and progressively fewer resources assigned to housekeeping all facilitate the spread of this disease, as does our inability to achieve acceptable levels of hand hygiene among hospital staff.

However, all of these risks are present in hospitals across Canada. What is different about Montréal almost certainly is that this area had the misfortune to be the first to suffer the introduction of a new, hypervirulent

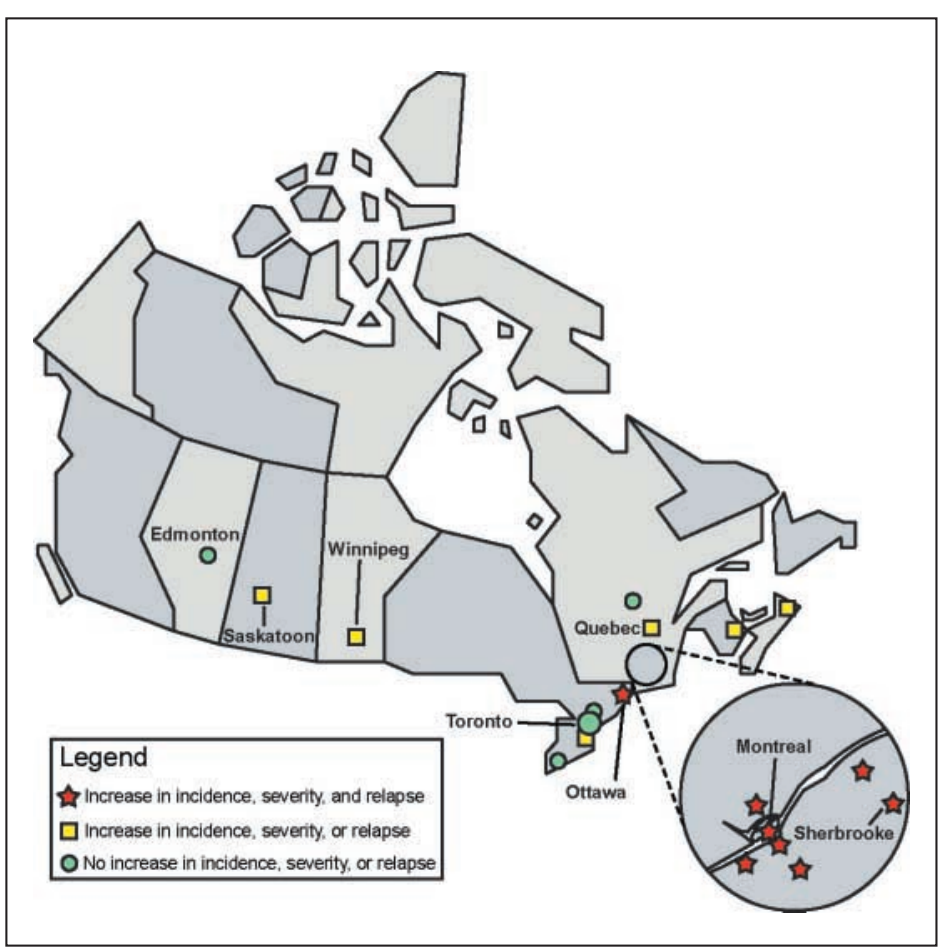

Fig. 2: Increases in incidence, severity and relapses of CDAD, based on a poll of 58 infectious disease physicians across Canada. and highly transmissible strain of C. difficile. Debilitated patients, deteriorating infrastructure and inadequate infection control practices provided a fertile soil for the establishment of the outbreak. This strain, or others similar to it, will almost certainly be introduced into hospitals across the rest of Canada in the next few months or years.

\section{What can be done?}

There are several issues that make outbreak control in Quebec difficult. There is no single reason for the outbreak, and the response to control must be multifaceted (see Box). We know little about the science of C. difficile outbreaks, and so we are dependent on expert opinion and extrapolations from other pathogens or situations in formulating recommendations for preventive interventions. Because these interventions are difficult and expensive, the absence of solid evidence makes them hard to justify: the alternative, however, is inaction, or inadequate action, which is clearly not an option. In addition, experience with epidemic strains of other hospital-acquired pathogens suggests that, once they are established in a geographic region, eradication is extraordinarily difficult. ${ }^{14}$ Finally, decades of underfunding and underresourcing of public health and infection control across Canada have result in hospital infection control programs that have insufficient human and other resources for the fight. For these reasons, we applaud the efforts of hospitals in Quebec and hope that their infection control programs receive the full support of hospital staff and administrations, public health and their provincial ministry. The battle will be long and difficult.

Hospitals in the rest of Canada will also be facing the challenges of outbreaks due to new, virulent strains. Hospitals, regions and provinces currently have three options. We can wait for the outbreak to happen and hope for the best. Alternatively, we can, each as individual hospitals, develop and implement plans to attempt to recognize the outbreak early on and, using lessons learned in Quebec, introduce changes in structure and practice that we hope will reduce the risk of outbreaks. Given that $C$. difficile is an old disease, that the basics of control programs are pretty boring compared to genomics, molecular diagnostics and MRI machines, and that hospital, provincial health care and research funding agency budgets are stretched, it will be difficult for us to change.

Then there is the third option. Could the infectious diseases and public health community use the experience from SARS to bring together the expertise and obtain the resources needed to provide answers to questions that are essential to address this problem, and to ensure that hospitals have the data, resources and encouragement necessary to develop proactive and effective prevention programs? This choice may seem expensive, and it will be, in the short term. However, we are going to pay for $C$. difficile one 
way or another - the choice is not whether to pay, but whether to pay for prevention or for treatment. In the mid- and long-term, paying for prevention will require less money and save lives.

\section{Louis Valiquette \\ Donald E. Low \\ Jacques Pépin \\ Allison McGeer}

From the Department of Microbiology, Mount Sinai Hospital, Toronto, Ont. (Valiquette, Low, McGeer) and the Department of Microbiology and Infectious Diseases, University of Sherbrooke, Sherbrooke, Que. (Valiquette, Pépin)

\section{References}

1. Eggertson L, Sibbald B. Hospitals battling outbreaks of $C$. difficile. CMA7 2004;171(1):19-21.

2. Alfa MJ, Du T, Beda G. Survey of incidence of Clostridium difficile infection in Canadian hospitals and diagnostic approaches. 7 Clin Microbiol

\section{Key interventions to prevent nosocomial transmission of} Clostridium difficile-associated diarrhea ${ }^{10}$

\section{Surveillance}

- Rapidly identify changes in incidence associated with introduction of new strains

- Enable evaluation of intervention programs

- Ensure that diagnostic tests in use are adequate to detect circulating strains

- Ensure early identification of emerging antimicrobial resistance

Prevention of patient-to-patient transmission

- Improve compliance with hand hygiene

- Diagnose C. difficile-associated diarrhea promptly

- Use private rooms and contact precautions for patients with suspected or diagnosed C. difficile-associated diarrhea; cohort patients if necessary

- Ensure appropriate and adequate cleaning of the hospital environment with agents active against $C$. difficile spores

- Introduce individually assigned thermometers and blood pressure cuffs; ensure that all other equipment that moves from patient to patient is adequately disinfected

- Incorporate infection control expertise from the earliest stages of planning for new building and renovation in health care

\section{Protection against gastrointestinal flora}

- Develop multidisciplinary interventions that include guidelines, education, monitoring and feedback to optimize prescribing, with the goal of selecting lower risk antibiotics

- Re-evaluate indications for perioperative antibiotic prophylaxis

Provide prompt and adequate therapy for infection

- Consider diagnosis, order cytotoxin assay of stool samples and provide results of testing promptly

- Introduce and implement guidelines for empirical treatment of diarrhea pending results of cytotoxin assay or endoscopy
1998;36(7):2076-80.

3. Hyland M, Ofner-Agostini M, Miller M, Paton S, Gourdeau M, Ishak M. N-CDAD in Canada: results of the Canadian Nosocomial Infection Surveillance Program 1997 N-CDAD Prevalence Surveillance Project. Can F Infect Dis 2001;12(2):81-8.

4. Carling $\mathrm{P}$, Fung $\mathrm{T}$, Killion A, Terrin N, Barza M. Favorable impact of a multidisciplinary antibiotic management program conducted during 7 years. Infect Control Hosp Epidemiol 2003;24(9):699-706.

5. Olson MM, Shanholtzer CJ, Lee JT, Jr., Gerding DN. Ten years of prospective Clostridium difficile-associated disease surveillance and treatment at the Minneapolis VA Medical Center, 1982-1991. Infect Control Hosp Epidemiol 1994;15(6):371-81.

6. Brooks SE, Veal RO, Kramer M, Dore L, Schupf N, Adachi M. Reduction in the incidence of Clostridium difficile-associated diarrhea in an acute care hospital and a skilled nursing facility following replacement of electronic thermometers with singleuse disposables. Infect Control Hosp Epidemiol 1992;13(2):98-103.

7. Karlstrom O, Fryklund B, Tullus K, Burman LG. A prospective nationwide study of Clostridium difficile-associated diarrhea in Sweden. The Swedish C. difficile Study Group. Clin Infect Dis 1998;26(1):141-5

8. Kyne L, Hamel MB, Polavaram R, Kelly CP. Health care costs and mortality associated with nosocomial diarrhea due to Clostridium difficile. Clin Infect Dis 2002;34(3):346-53.

9. Archibald LK, Banerjee SN, Jarvis WR. Secular trends in hospitalacquired Clostridium difficile disease in the United States, 1987-2001. I Infect Dis 2004;189(9):1585-9.

10. National Clostridium difficile Standards Group. Report to the Department of Health. 7 Hosp Infect 2004;56 (Suppl 1):1-38.

11. Morris AM, Jobe BA, Stoney M, Sheppard BC, Deveney CW, Deveney KE. Clostridium difficile colitis: An increasingly aggressive iatrogenic disease? Arch Surg 2002;137(10): 1096-100.

12. Dallal RM, Harbrecht BG, Boujoukas AJ, Sirio CA, Farkas LM, Lee KK, et al. Fulminant Clostridium difficile: an underappreciated and increasing cause of death and complications. Ann Surg 2002;235(3):363-72.

13. Dial S, Alrasadi K, Manoukian C, Huang A, Menzies D. Risk of Clostridium difficile diarrhea among hospital inpatients prescribed proton pump inhibitors: cohort and case-control studies. CMA7 2004;171(1):33-8.

14. Muto CA, Jernigan JA, Ostrowsky BE, Richet HM, Jarvis WR, Boyce $\mathrm{JM}$, et al. SHEA guideline for preventing nosocomial transmission of multidrug-resistant strains of Staphylococcus aureus and enterococcus. Infect Control Hosp Epidemiol 2003;24(5): 362-86. 